Bertil Hanström

Zoological Papers in honour of his sixty-fifth Birthday, November 20th, 1956. Edited by Karl Georg Wingstrand. Pp. 312. (Lund : Zoological Institute, 1956.) $50 \mathrm{Sw}$. Kr.

CCRUTINY of these papers soon reveals that they $\$$ mark more than a formal occasion. In offering them to Prof. Bertil Hanström, the contributors have taken obvious pleasure in expressing their gratitude to him " . . a as a teacher and leader of the Zoological Institute in Lund".

Prof. Hanström's first paper was published in 1915, and it dealt with the birds of the island of öland. While his subsequent work has been mainly concerned with nervous systems, particularly with neurosecretion, Hanström still finds time for field studies. It is thus not surprising that Lund is now an important centre for systematic, zoogeographical and ecological work.

Hanström's interests are clearly reflected in this series of papers. As might be expected, there are several papers on neural and neurosecretory systems (concerning insects, chilopods, crustaceans, cephalopods and the toad, Bufo bufo). Others deal with the systematics and relationships of crustaceans, ecology and cytology. The range of these papers shows clearly that zoology is in a flourishing state at Lund.

The contributions are nicely produced and bound, the design for the cover being particularly appropriate.

N. B. Marshali

\section{Diagnostic Performance Tests}

A Manual for Use with Adults. By Boris Semeonoff and Eric Trist. Pp. $\mathrm{xv}+176+4$ plates. (London : Tavistock Publications, 1958.) 32s. net.

$A \mathrm{~S}$ is well known, intelligence tests were evolved in order to detect and assess educationally subnormal schoolchildren. Their intention was to sample mental growth in its various aspects and to provide reliable standards of performance in relation to age. By and large they succeeded admirably. In the case of adults, on the other hand, mental testing has proved altogether less satisfactory. Although a wide variety of tests purporting to measure adult intelligence exists, it is seldom clear precisely what is being measured or how much confidence can be placed in the results. In consequence, the use of intelligence tests with adults has beon viewed-in Britain at least-with understandable reserve.

The methods of testing intelligence described in this book have an unusual history. In 1940, Mr. Trist was concerned to develop some tests of intellectual deterioration due to injury or disease of the brain. In the light of the work of Goldstein and others, it had become plain that such deterioration is particularly liable to show itself in performances involving abstraction, spatial analysis and sequential learning. Mr. Trist was therefore led to devise a small battery of tests well adapted to reveal defects in these fields. But it soon became clear not only that extensive control data were necessary but that the techniques might have important application to the assessment of healthy individuals. At this point Dr. Semeonoff entered the picture and was able to carry the work very much further. Indeed, the present book is very largely the outcome of his prolonged and patient endeavour.

The performance tests reported here have the advantage first, that they make little demand upon linguistic sophistication; and secondly, that they permit some evaluation of important aspects of personality. Indeed, the emphasis throughout is upon assessment of the individual as a whole rather than upon some arbitrary dimension of intellect or temperament. In consequence, these tests may be expected to find application not only in clinical psychology but in any field of personnel selection in which considerations of temperament are relevant.

This battery of tests is perhaps the first to be evolved in part at least on a neurological basis. If it be conceded that the brain has at any rate something to do with intelligence, this would seem a notable-if belated-achievement.

O. L. Z Z ANGWILL

\section{A Study of Blackbirds}

By Dr. D. W. Snow. Pp. 192. (London: Ceorge Allen and Unwin, Ltd., 1958.) 21s. net.

$\mathrm{B}$ EFORE the natural history of a wild species can be understood it must be studied from more than one point of view-only when behaviour, ecology, systematic position and other aspects of its biology are inter-related can a full picture be obtained. This book describes a study in which much progress has been made in this direction. Based on four years work in the neighbourhood of the Botanic Garden, Oxford, it presents intimate details of the history of a small community of blackbirds, many of which were colourringed. Although written in non-technical language (much of the material has also been published in scientific journals), the author places his observations against a wide background of biological principles, and thus provides material both for the general ornithologist and for professional biologists.

As well as descriptions of the life-history, displays and vocalizations of the blackbird, many interesting facts which could have come only from a close study of colour-ringed birds are presented-for example, the pairs which are sometimes formed in winter are only temporary affairs; and male and female feed different individual young after the brood has left the nest.

Perhaps the most interesting chapters are those which deal with population problems. In particular, a contrast is drawn between garden and woodland populations. The former are dense, with a high breeding success, and produce an excess of young birds which do not disperse before settling. Under these conditions, territorial behaviour limits breeding density. Woodland, on the other hand, is sparsely populated, and breeding success is low ; population density is probably controlled largely by survival in the preceding winter.

R. A. HINDE

\section{Proceedings of a Symposium on Insect and Food- plant}

Wageningen, May 27-29, 1957, under the auspices of the Comité Européen de Zoologie Agricole (C.E.Z.A.) and the Agricultural University, Wageningen. Pp. 118. (Wageningen: Landbouwhoogeschool Laboratorium voor Entomologie, Berg 37, 1958.) 5 florins. GYMPOSIA are becoming increasingly used as a $\$$ means of communication between scientists ; subsequent publication of the reviews and discussions often go far to help the research worker to keep abreast of the latest ideas and results of others. According to the preface of the proceedings of this symposium, the organizers had hoped to obtain during the discussions "a synthetic view of the whole complex of insect - host-plant interactions". Although this aim was, unfortunately, not achieved, 